\title{
Spatial risk perception among 9th grade students mainland Portugal versus the metropolitan area of Porto
}

\section{Bruno Martins, Adélia Nunes \& Luciano Lourenço}

To cite this article: Bruno Martins, Adélia Nunes \& Luciano Lourenço (2019) Spatial risk perception among 9th grade students mainland Portugal versus the metropolitan area of Porto, International Research in Geographical and Environmental Education, 28:3, 194-210, DOI: 10.1080/10382046.2018.1561632

To link to this article: https://doi.org/10.1080/10382046.2018.1561632

曲 Published online: 19 Jan 2019.

Submit your article to this journal $\pi$

Џlll Article views: 73

Q View related articles 두

View Crossmark data $\llbracket$ 


\title{
Spatial risk perception among 9th grade students mainland Portugal versus the metropolitan area of Porto
}

\author{
Bruno Martins (D), Adélia Nunes (D) and Luciano Lourenço (DD \\ Department of Geography and Tourism, Faculty of Arts and Humanities, CEGOT, RISCOS, University \\ of Coimbra, Coimbra, Portugal
}

\begin{abstract}
This study aims to assess the perception that 9th year students have about some key concepts related to the "science of risk" and to evaluate their ability to identify and classify the natural and mixed risks with a greater probability of occurrence, both at national level and in the Metropolitan Area of Porto (MAP). A questionnaire was applied to 308 students in the 9th year, before the content was taught in geography classes. The results show that students have major difficulties when assessing concepts (such as susceptibility, vulnerability and disaster) and the causes, consequences and mitigation measures identification were evaluated by them as the most important local/municipal risks. In general, the students rated forest fire as the risk most likely to occur, both nationally and in all the MAP municipalities, with a classification of high (national) and moderate (MAP). At municipal level, however, some differences were highlighted in the ranking for the different types of risk. These results also suggest that risk perception is shaped by informal sources of information such as that provided by mass media, and the proximity to a certain type of risk.
\end{abstract}

\section{KEYWORDS}

9th year students; geography education; metropolitan area of Porto; Portugal; risk perception

\section{Introduction}

The increase in the occurrence of disasters has generated an overall growing interest in the subject, especially since the mid-1950s. The economic and social costs involved are substantial, relating not only to human loss and economic damage, but also to the recovery/reconstruction of the affected areas. At the same time, it is acknowledged that if a portion of the population were to adopt suitable behaviour in terms of either preventing or managing natural risks this could bring about a reduction in the consequences of the occurrence of risk (Ardaya, Evers, \& Ribbe, 2017; Becker, Aerts, \& Huitema, 2014).

Without neglecting factors associated with susceptibility, the extent of people's exposure to risks also significantly affects their vulnerability and therefore the consequences of the occurrence of risks (Smith, 1996; Cunha \& Dimuccio, 2002; Rebelo, 2008; Oliveira et al., 2017). This is why people's involvement is vital for more

CONTACT Bruno Martins bmscmartins@gmail.com $\Theta$ Department of Geography and Tourism, Faculty of Arts and Humanities, CEGOT, RISCOS, University of Coimbra, 3004-530, Coimbra, Portugal 
effective risk management (Dixit, 2003). In this regard, many authors note that seeing crises as merely a technical issue and ignoring the importance of community involvement, in particular how the public perceives them, is an error in terms of the crisis management process (Slovic, 1987; Lebel, 2006; Birkholz, Muro, Jeffrey, \& Smith, 2014; Bodoque et al., 2016). Perception thus plays a major part in motivating individuals to take action to avoid, mitigate, adapt to, or even ignore risks (Wachinger, Renn, Begg, \& Kuhlicke, 2013). Several authors (Muttarak \& Lutz, 2014; Bardsley, 2017) also consider that people who are well-educated are better able to plan for and respond to risk, both individually and collectively. All perceptions are interpreted in accordance with prior knowledge and existing beliefs (Gerstenmaier \& Mandl, 1995), so investigating preconceptions is a crucial factor in the education-learning process, and particularly important in the field of geography (Schubert, 2015). Spatial associations are also significant for risk perception (Wachinger et al., 2013). In this context, understanding the causes, impacts and geographical patterns of local hazards is important for helping people to make educated decisions about how to respond to the threat they pose (Battersby, Mitchell, \& Cutter, 2011). The United Nations Children's Fund (2011) consider that students of all ages can actively study and participate in school safety measures and also work with teachers and other adults in the community towards minimising risk before, during and after disaster events. In fact, children tend to be more enthusiastic and receptive to education related to hazards and can serve as a conduit to transfer their new knowledge about hazard preparedness to their family and friends (Battersby et al., 2011; Wachinger et al., 2013). Risk reduction education is thus one of the most important and powerful tools in forming new concepts, changing habits and fostering intergenerational dialogue. It plays a pivotal and structuring role in the implementation of mechanisms that lead to better-prepared citizens and more resilient societies, which will help to increase awareness of risks and perceive danger better.

Thus the worldwide campaign Disaster risk reduction begins at school, pursued in 2006 and 2007 by the International Strategy for Disaster Reduction (ISDR 2007) an outcome of the World Conference on Disaster Risk Reduction, which took place in Japan in 2005, sought to inform and mobilise governments so that disaster risk reduction became part of the school curricula in primary and secondary schools, to increase countries' resilience in the face of disaster.

It was only in 2011 that Portugal, through the National Education Council, via Recommendation no. 5/2011, decided that schools should promote risk education, including relevant material in their curricula about different risk conceptions and approaching the issue not only by sharing information and knowledge, but also by promoting action that, in practice, deals with specific cases of risk. In this way, it was hoped to "transform schools into active participants and stimulate civil society's involvement in matters related to Risk Education, via students, their families and the rest of the education community" (Nunes, Almeida, \& Nolasco, 2013).

Nevertheless, the Portuguese geography curriculum guide proposed under the 2001 reforms had already introduced the subtopic of "Risks and Natural Disasters" for lower secondary education (3rd cycle), in which content relating to the Causes of natural disasters and the Effects on humankind and the environment is explored. 
However, the recommendations stemming from the curriculum guidelines seem manifestly insufficient, as they only considered the causes and effects of disasters, without any reference to an explanation of basic concepts such as risk and disaster, or the definition of different types of risk. On the other hand, the teaching/learning process should focus on the prevention and mitigation of disasters, important aspects for creating a culture of prevention that could lead to a reduction in negative effects (Tedim, Ferreira, Cunha, \& Sousa, 2010). In the 2015/16 academic year, an initiative by the Ministry of Education and Science saw the subject Risks, Environment and Society introduced into the curriculum of the 9th year students (Nunes et al., 2013/14). The first aim was to understand/explain a series of concepts related to risk theory such as suscetibility, vulnerability, risk and disaster. Other objectives were the identification of different risks in relation to their causes (natural and mixed) and consequences, and the mitigation of their impacts.

Also launched in 2015 was the Reference for Risk Education (RERisco), a joint project from the Directorate General for Education (DGE), Directorate General for Schools (DGstE) and the National Civil Protection Authority (ANPC) aimed at pre-school, primary and secondary students. A wider project concerning Education for Citizenship, was designed to help implement risk awareness education within the framework of Citizenship Education, in its cross-cutting dimension and in the development of projects and initiatives that contribute to the personal and social education of students, and also in the range of complementary curricular activities available in the 1st, 2 nd and 3rd cycles of basic education.

Although concerns about Risk reduction education within the school context are at an embryonic stage in Portugal, this study set out to assess:

i. Year 9 students' preconception of fundamental concepts associated with the science of risk (such as risk, disaster, susceptibility and vulnerability);

ii. the awareness of spatial dimension that students have about natural and mixed risks that affect both mainland Portugal and the area where they live, in this case, some municipalities in the Metropolitan Area of Porto (MAP);

iii. whether the students are able to identify the causes, consequences and mitigation measures for the risk that they consider most likely to occur in their area of residence.

In addition, in accordance with the USA's National Research Council (NRC), this exercise is also intended to analyse these students' spatial thinking. The educational aim is not just to promote the habit of thinking spatially but also to foment the practice of spatial thinking in an informed manner and the adoption of a critical attitude to spatial thinking (NRC, 2006).

\section{Geographical environment of the MAP}

The MAP comprises 17 municipalities with an area of $2,040 \mathrm{~km}^{2}$, located in the North of Portugal (Figure 1). Its resident population in 2017 was 1,759,524, distributed across the 17 municipalities (Portuguese National Statistics Institute INE, 2018). 

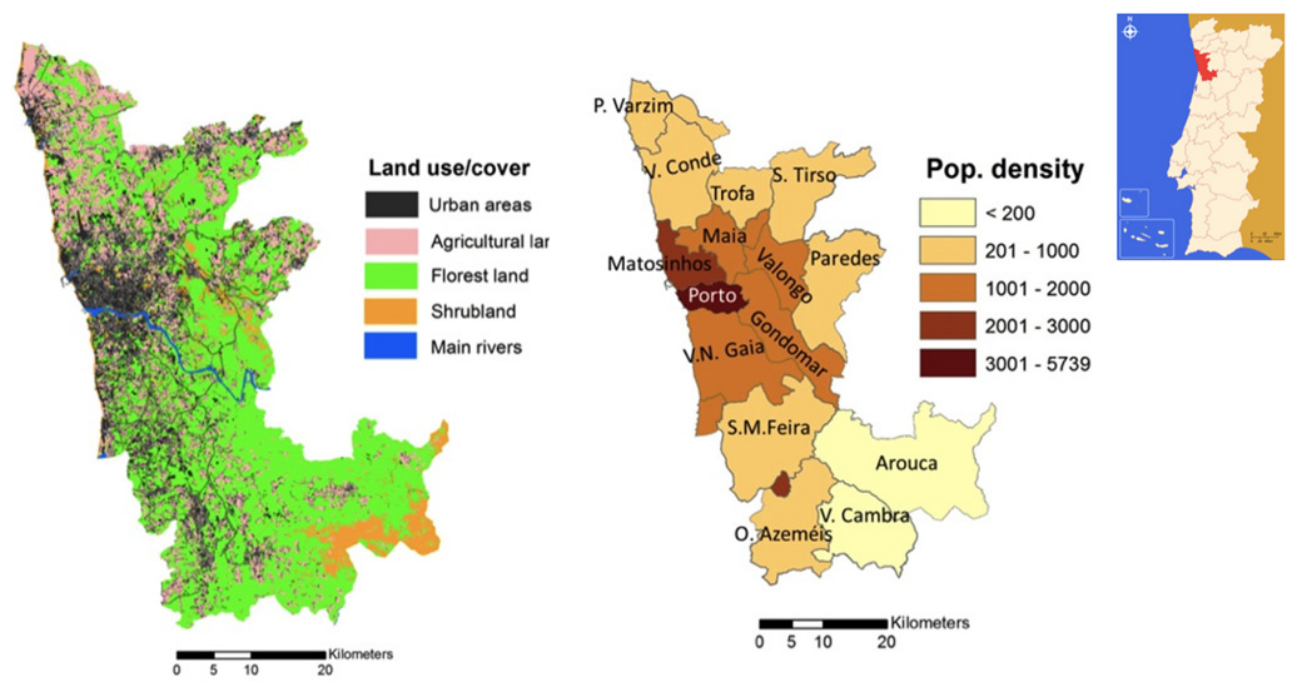

Figure 1. Location of the MAP, land use/cover in 2015 and population density at municipal level, in 2017. (Source: Land use/cover adaped from the Land Use and Land Cover Map of Continental Portugal, 2015, Directorate-General for the Environment; Population density was compiled from the Portuguese National Statistics Institute, 2018).

In socio-economic, environmental and population density terms, the MAP is a very heterogeneous area in many ways, with coexisting urban, rural and forested areas (Figure 1). On the basis of the land use/land cover map (2015) $\sim 34 \%$ of the land is forested, $24 \%$ is agricultural and $28 \%$ consists of impermeable land, which correspond mainly to urban areas. The forests consist mainly of eucalyptus, especially in the municipalities of Valongo, Gondomar and Vila Nova de Gaia (VNG), and of a combination of pines and eucalyptus in the municipalities of Póvoa de Varzim and Vila do Conde.

In terms of frequency and the magnitude of impact, hydro-meteorological risk, geomorphological risks and the risk of forest fires stand out. The most significant hydro-meteorological risk is that of flooding, especially related to the River Douro. Between 1526 and 2009, 135 serious incidents have been recorded that affected the riverbank areas of Porto and VNG (Almeida, 2011).

The municipal strategy of adapting to climate change (EMAAC) suggests that meteorological risks are considered low in the municipality of Porto. The most immediate of these risks are heatwaves. These have a significant impact on energy consumption for domestic air conditioning systems and water use for domestic irrigation, which affect household budgets and people's health. Events related to high rainfall, of short duration but high intensity (resulting in floods) are considered priority risks with a tendency to be exacerbated against the backdrop of climate change (EMAAC, 2016).

Geomorphological risks principally take the form of landslides, subsidence and rockfall, fairly common in the historical centres of Porto and VNG and along the cliffs that border the riverbank areas of these municipalities. Rockfalls often occur on the Serra do Pilar cliffs (VNG), related to strong decompression and formation of 
fractures in the massif, and this has justified intervention projects involving the bolting and cabling of the cliffs.

Coastal erosion along the shoreline of the MAP's municipalities is associated with frequent overtopping incidents, in particular in Póvoa de Varzim, Vila do Conde, Porto, VNG and Espinho. They are linked to the construction of infrastructure (the port of Leixões and groynes) and rough seas, especially around the time of the equinoxes, with a significant impact on the rates of erosion and accretion. Apart from the municipality of Porto, all the municipalities are highly susceptible to forest fires.

\section{Methodology}

To ascertain Year 9 students' perceptions of basic concepts associated with Risk Science as well as assessing their ability to identify and classify the natural and mixed risks most likely to occur across Portugal and within the MAP, a questionnaire was administered before the topic was taught in geography classes, the content of which lies within the Risks, Environment and Society domain.

The questionnaire was given to a total of 308 students in Year 9 (lower secondary education), aged between 14 and 16, who attend schools in the MAP, but more specifically in the municipalities of Matosinhos, Porto, VNG and Gondomar. This questionnaire was given to them in April 2017, before they became acquainted with the topic of risk.

The questionnaire is divided into three sections. The first aims to appraise Year 9 students' knowledge of the basic concepts associated with Risk Science, these being susceptibility, vulnerability, risk and disaster. These concepts were chosen based on their importance in the conceptual-operational risk-hazard-crisis model. A choice of four answers was offered for each concept. The students were asked to identify which one they thought was correct.

The second part of the questionnaire set out to assess the students' ability to identify spatial associations by classifying the likelihood of natural and mixed risk incidents occurring nationally, and in the municipality where they live. For this purpose, 16 natural and mixed risks were listed which had to be rated using a qualitative scale ranging from null/least to a maximum amount. This corresponded to a quantitative scale from 1 to 5 , as follows: 1 - null/least; 2 - reduced; 3 - moderate; 4 - high; 5 maximum. Thus, the lowest number (null or least) is associated with a very low perception of risk based on the probability of a risk occurring, while the highest number (maximum) is associated with a very high probability of the risk occurring.

Then, the numbers obtained for the national and municipal levels were standardised, with a total possible score of 100. The remaining amounts were standardised based on this total score $(=100)$, which allowed the risks to be hierarchically organised in terms of how likely they are to occur.

Next, to detect homogenous groups in the collected data, the cluster analysis approach was used, in other words, a multivariate approach (Pestana \& Gageiro, 1998). Indeed, hierarchical cluster analysis is one of the methods used to measure the hierarchy of the proximity between objects, which in this case are risks. The average linkage technique was used to achieve this. Some of the characteristics of this method 
are lower sensitivity to noise than shown by nearest-neighbour chain methods and complete linkage clusterings presentation of good results for Euclidean distances and other distances, and a tendency to form groups with a number of similar elements (Kaufman \& Rousseeuw, 1990). The dendrogram is thus the diagrammatic representation of the proximity matrix among samples, given that it organises the risks according to their similarity or dissimilarity as perceived by the students, both nationally and in the municipality where they live.

Subsequently, the degree of linear correlation between the results obtained both at national level and in the various municipalities was measured using the Pearson correlation coefficient $(r)$, a dimensionless index with values between -1.0 and 1.0 that reflects the intensity of the linear relationship between two sets of data.

Finally, the results of the third part of the questionnaire are presented, in which three questions were posed with the objective of gauging the students' knowledge regarding the causes, consequences and mitigation measures for the risk that they considered most frequent in the municipality where they live.

SPSS Version 20.0 (IBM Corporation, Somers, NY) was used for data analysis for both descriptive statistics and correlation analysis. The differences in risk perception are shown through a comparison of the geographic differences.

\section{Results}

\section{Basic concepts associated with risk science}

Just over half the students surveyed (51.3\%) responded correctly when they were asked to identify the concept of Risk, which they understood as being "The combination of the probability of dangerous event and its negative consequences" (UNISDR, 2009). The other options, "events with relatively limited effects in time and space, likely to cause damage to people and property"; "manifestation of physical, technological and manmade phenomena and the respective effects on people and property" and "physical and human consequences arising from the occurrence of dangerous phenomena" had a very similar response rate, close to $15 \%$ (Figure $2 \mathrm{a}$ ).

With regard to the concept of Disaster, the correct option, "a serious disruption of the functioning of a community or a society involving widespread human and environmental losses and impacts" (UNISDR, 2009) obtained only $17.2 \%$ of the responses, an amount significantly lower than $46.9 \%$, the percentage that opted for "a huge disaster, due to high human and material losses", which certainly arises from the fact that students took into account only the most visible part of disasters, which is naturally their serious consequences. Along the same line of thought, around $30 \%$ believed a disaster to be "damage that a natural phenomenon causes to a given population". The remaining 3.9\% believed it to be "an event that results from the failure to control hazardous chemical products" (Figure 2b).

With regard to the concept of Susceptibility, it was understood by the majority (around $38 \%$ of students) to be "an area's propensity to be affected by a natural disaster". The correct answer, "conditions prevailing in a specific area that favour the occurrence of a destructive phenomenon", obtained a slightly a lower score, $27 \%$ of answers, probably because the two answers were somewhat similar, something that 

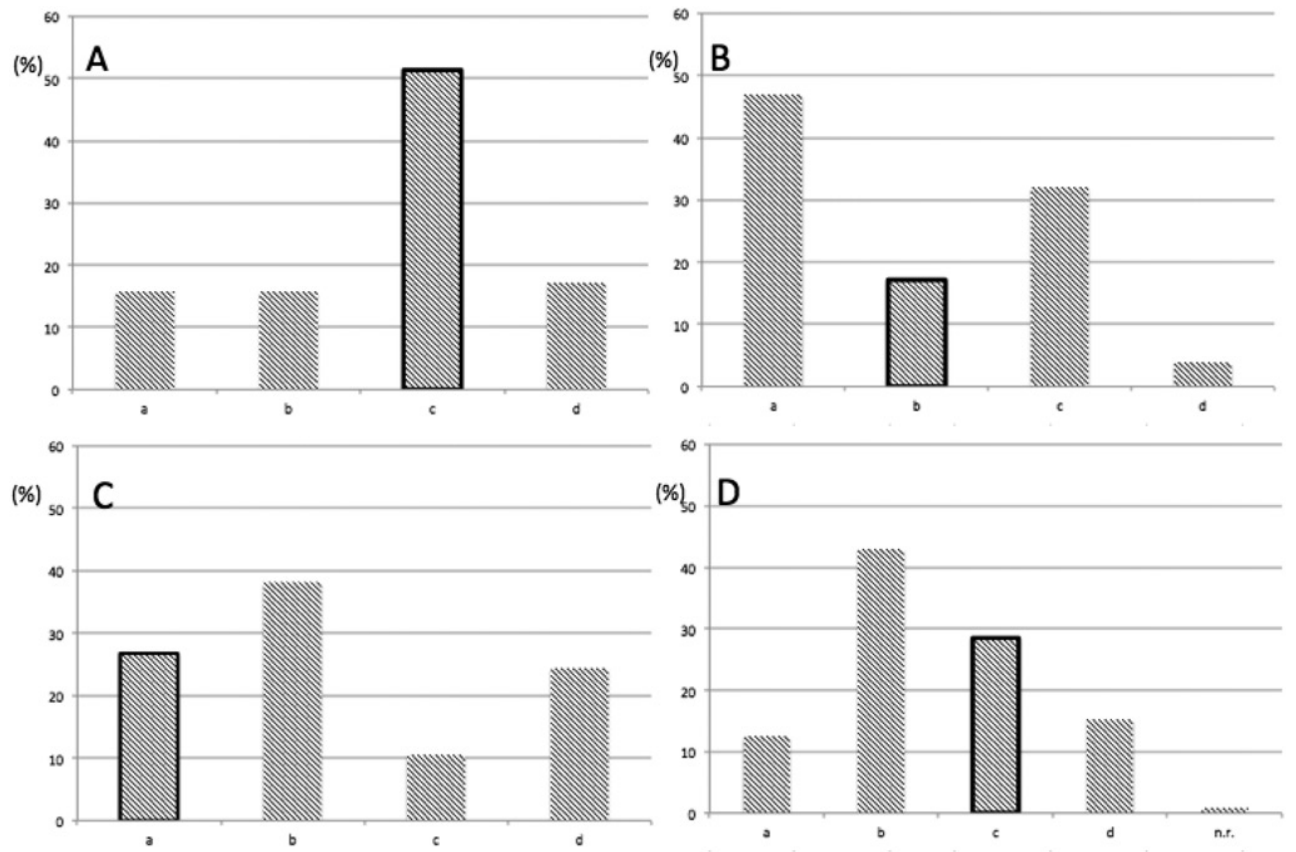

Figure 2. Distribution (in \%) of the answers to the concepts of Risk (a), Disaster (b), Susceptibility (c) and Vulnerability (d).

needs to be corrected for future use of the questionnaires. The option "natural and human elements exposed to a particular risk" received a score very close to that obtained in the previous answer, 24.4\%. The remaining $10.0 \%$ understood susceptibility as corresponding to a "high risk geographical area" (Figure 2c).

In turn, the concept of Vulnerability was understood by $43 \%$ of the students to be a "geographical area more exposed to a natural or manmade risk", a score significantly higher than the correct option, "characteristics and circumstances of a community, system or asset that make it susceptible to the damaging effects of a hazard" (UNISDR, 2009) which received a total of slightly under 30\%. The options "the affected population's capacity to respond to a dangerous phenomenon" and "protection measures tested before the occurrence of a natural, technological or manmade phenomenon" received 15.2 and $12.5 \%$, respectively (Figure $2 \mathrm{~d}$ ).

\section{Spatial perception: Portugal mainland vs MAP level}

The systematic qualitative and quantitative distribution of the likelihood of different risks as perceived by 9th year students both nationally and within the MAP are highlighted in Table 1. In general, the perception the students had of the spatial dimension of natural and mixed risks, based on how likely they are to occur, ranged between reduced and moderate for around $60 \%$ of respondents when considered at national level, and between minimum and reduced for more than $65 \%$ of respondents when only the MAP was considered. 
Table 1. Distribution of the relative frequencies (\%) by class, according to the occurrence of different risks at national level and within the MAP (most relative frequency classes shaded in grey).

\begin{tabular}{|c|c|c|c|c|c|c|c|c|c|c|}
\hline & \multicolumn{5}{|c|}{ Mainland Portugal } & \multicolumn{5}{|c|}{ Metropolitan area of Porto } \\
\hline & Null & Low & Moderate & High & Maximum & Null & Low & Moderate & High & Maximum \\
\hline Earthquakes & 14.3 & 46.9 & 27.4 & 9.4 & 2.0 & 56.2 & 30.8 & 10.7 & 1.8 & 0.5 \\
\hline Volcanoes & 48.4 & 33.7 & 11.4 & 5.2 & 1.3 & 85.3 & 10.4 & 1.6 & 2.0 & 0.7 \\
\hline Tsunamis & 29.6 & 40.5 & 18.1 & 8.6 & 3.3 & 55.4 & 33.0 & 7.1 & 3.5 & 0.6 \\
\hline Hurricanes & 35.4 & 40.7 & 14.4 & 6.2 & 3.3 & 60.0 & 28.4 & 9.5 & 1.4 & 0.6 \\
\hline Tornadoes & 30.2 & 44.3 & 17.0 & 6.2 & 2.3 & 56.3 & 29.5 & 11.2 & 2.4 & 0.6 \\
\hline Drought & 17.9 & 26.6 & 37.5 & 16.3 & 1.7 & 41.0 & 36.0 & 20.3 & 2.1 & 0.7 \\
\hline Heatwaves & 4.3 & 24.0 & 44.7 & 24.7 & 2.3 & 15.8 & 35.1 & 39.0 & 9.3 & 0.7 \\
\hline Cold spells & 6.3 & 25.5 & 43.4 & 22.5 & 2.3 & 12.6 & 31.1 & 44.7 & 11.5 & 0.2 \\
\hline Floods & 4.0 & 20.7 & 37.4 & 32.4 & 5.6 & 15.7 & 31.3 & 35.9 & 15.5 & 1.7 \\
\hline Landslides & 17.7 & 35.4 & 32.0 & 12.2 & 2.7 & 40.1 & 28.2 & 25.4 & 5.1 & 1.2 \\
\hline Air pollution & 5.2 & 19.5 & 35.8 & 28.3 & 11.1 & 11.8 & 28.3 & 34.5 & 19.3 & 6.1 \\
\hline Water pollution & 4.6 & 15.9 & 37.1 & 33.4 & 8.9 & 18.6 & 30.9 & 30.6 & 17.3 & 2.7 \\
\hline Soil degradation & 6.0 & 29.1 & 42.7 & 14.6 & 7.6 & 22.1 & 41.2 & 25.3 & 9.0 & 2.4 \\
\hline Desertification & 31.6 & 33.0 & 21.0 & 11.3 & 3.1 & 47.9 & 32.0 & 14.0 & 4.8 & 1.2 \\
\hline Forest fires & 0.7 & 5.9 & 18.4 & 49.2 & 25.9 & 14.3 & 23.6 & 30.2 & 23.0 & 8.9 \\
\hline Coastal erosion & 8.8 & 25.2 & 32.7 & 28.1 & 5.2 & 31.2 & 25.3 & 28.0 & 10.6 & 4.9 \\
\hline Mean & 15.8 & 28.7 & 29.9 & 20.1 & 5.5 & 35.3 & 29.8 & 23.7 & 9.1 & 2.1 \\
\hline
\end{tabular}

Rated as having a minimal to reduced probability of occurring at national level were geophysical risks, including the risk of volcanic activity and tsunamis, and some meteorological risks, particularly hurricanes and tornadoes. The perception of some students regarding the risk of desertification was also of a minimal/null probability of occurrence (Table 1).

Within the classes of reduced-moderate occurrence, seismic risk, droughts, cold spells, soil degradation and landslides attracted the dominant ranking. In the moderate to high categories, heatwaves, floods, water and air pollution, and coastal erosion stand out, with $60-70 \%$ of respondents choosing them. Forest fires had the greatest relative frequency, a total of $75 \%$, in the categories of high to maximum occurrence.

With regard to the MAP, the categories that saw greater relative accumulated frequencies, on average, were the minimum and reduced categories. In the case of geophysical risk, the values fluctuated between 88 and 96\%. Hurricanes and tornadoes also had almost identical values. In turn, the occurrence of droughts, landslide movements and desertification were perceived by the majority of students as having a null/ minimal to reduced risk of occurrence. Lastly, the remaining identified natural and mixed risks emerged with a greater probability of occurrence, even though the greatest frequency percentage is in the reduced to moderate categories. Only forest fires stand out, which $23 \%$ of the students rated as having a high probability of occurring in the MAP.

\section{Spatial ranking of risks}

Quantifying students' perception of the spatialisation of different types of risks allowed them to be placed in hierarchical order, to identify more specifically the assessment of risks based on their occurrence, both at national level and within the municipality where they live.

At national level, the risk of forest fires is evident. Nationally, forest fires are common, especially in the North and Centre of Portugal (Leite, Gonçalves, \& Vieira, 


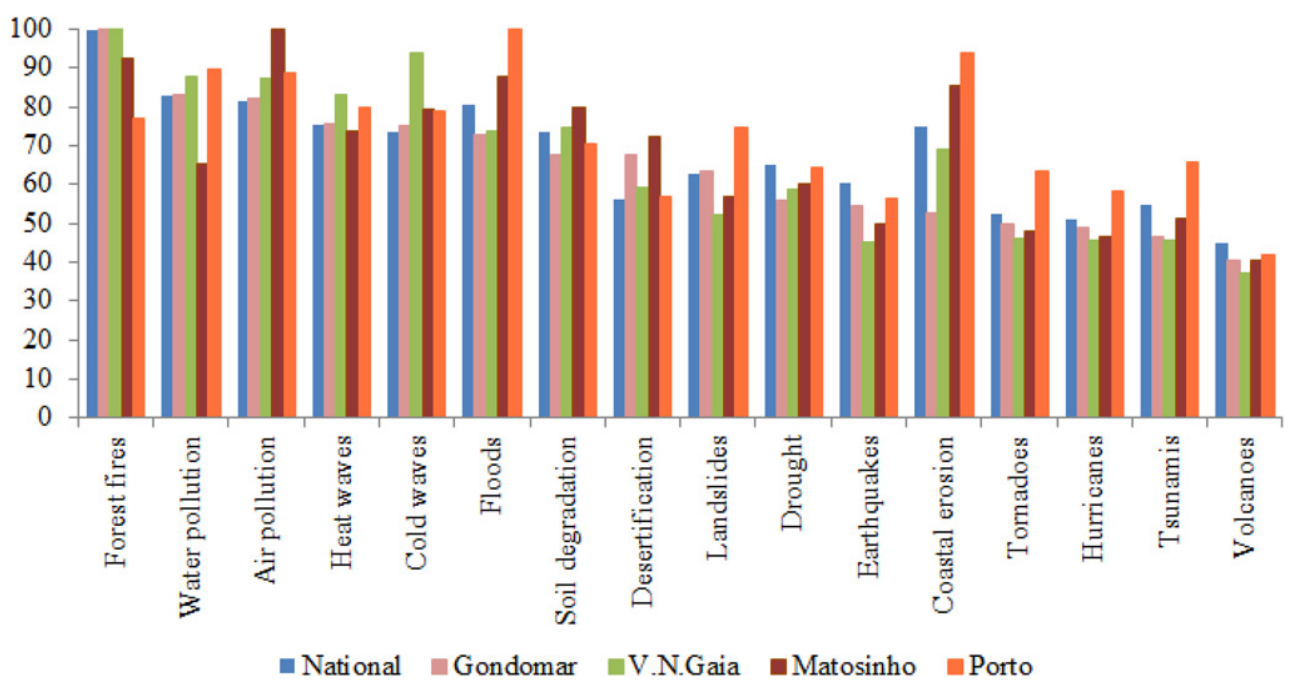

Figure 3. Ranking of the risks analysed for the national and municipal areas, according to the students' perception.

2011; Nunes, 2012; Nunes, Lourenço, \& Meira, 2016). This is widely reported in the media, which naturally turns them into a risk with a high probability of occurrence.

And yet, at a municipal level they only come in first place in the municipalities of Gondomar and Gaia. In Matosinhos, they take second place and students chose air pollution as the risk with the greatest probability of occurrence. Within the municipality of Porto the risk of floods caused the greatest concern for students and they placed this at the top in terms of occurrence. This is not altogether surprising given that it is almost entirely an urban municipality, with practically no records of forest fires.

At national level, however, water and air pollution were highlighted as risks on a par with floods, as they were perceived as having the highest risk of occurrence. But in the municipalities of Gondomar and Gaia, the risks of heatwaves and cold spells were in top position, while risk of coastal erosion was prominent in the municipalities of Porto and Matosinhos.

Lastly, the risk of volcanic activity was perceived at both a national and municipal level as having a reduced risk, and came last in the ranking after earthquakes, hurricanes, tornados and tsunamis collectively, although in different positions (Figure 3).

\section{Similarity and correlation between the national and municipal scales}

The use of hierarchical cluster analysis for students' perception of the spatialisation of the different types of risks shows that, at national level, they pinpointed the occurrence of forest fires above the remaining risks' probability of occurrence. The intensive occurrence of this risk, particularly in the North and Centre of Portugal, widely reported by the media, will certainly explain this perception (Figure 4).

In a second group, they pinpointed those risks that were perceived as occurring less often, namely hurricanes, tornadoes, tsunamis, desertification and volcanic activity. 


\section{Dendrogram using Average Linkage (Between Groups)}

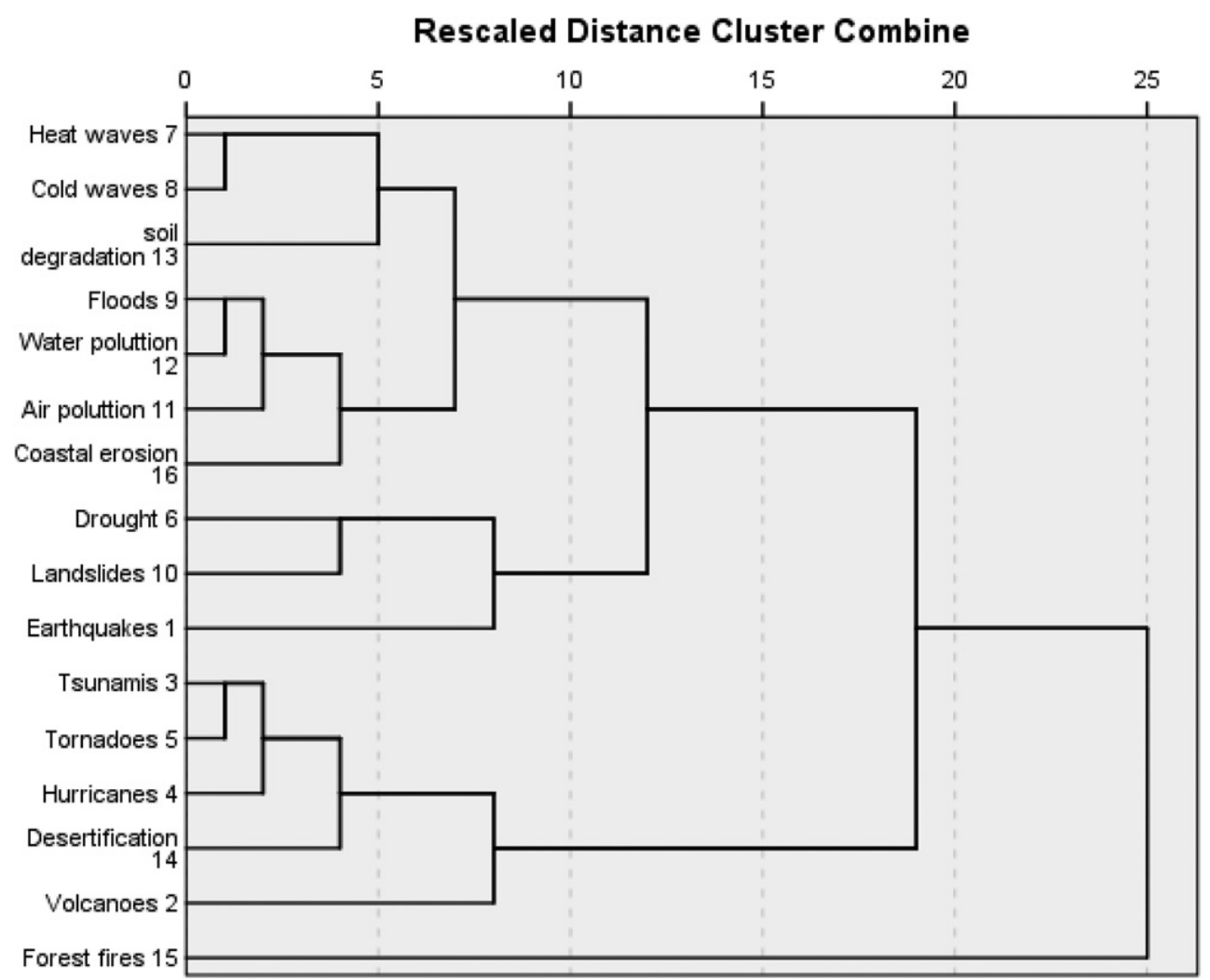

Figure 4. Hierarchical analysis of clusters regarding the occurrence of different risks at national level.

In a third cluster, the remaining risks are divided into two subgroups: one includes floods, water pollution, air pollution and coastal erosion, along with cold spells, heatwaves and soil degradation; and the other is formed by droughts, landslides and earthquakes.

At municipal level, the results show slight similarities and discrepancies, both amongst themselves and compared to the national figures, which deserve attention (Figure 5). As such, the risk of forest fires is not pinpointed as a cluster in any of the municipalities, contrary to the perception on a national scale. In fact, it was included in the cluster of other risks with a greater potential for occurrence, along with the risk of air and water pollution.

In this way, students from the municipality of Porto pinpointed volcanoes as being a risk with zero probability of occurring, and the other risks were included in two main subgroups. Despite not following the same pattern, the similarity in the aggregation of the risks is notable and only differs with regard to soil degradation, which is perceived as less relevant in the municipality of Porto than in VNG, in contrast to landslides which were perceived as more important in the municipality of Porto than in VNG (Figure 5a, b).

Applying hierarchical cluster analysis to the municipalities of Matosinhos and Gondomar results in the emergence of two main groups of risks, which contain risks 


\section{Dendrogram using Average Linkage (Between Groups)}

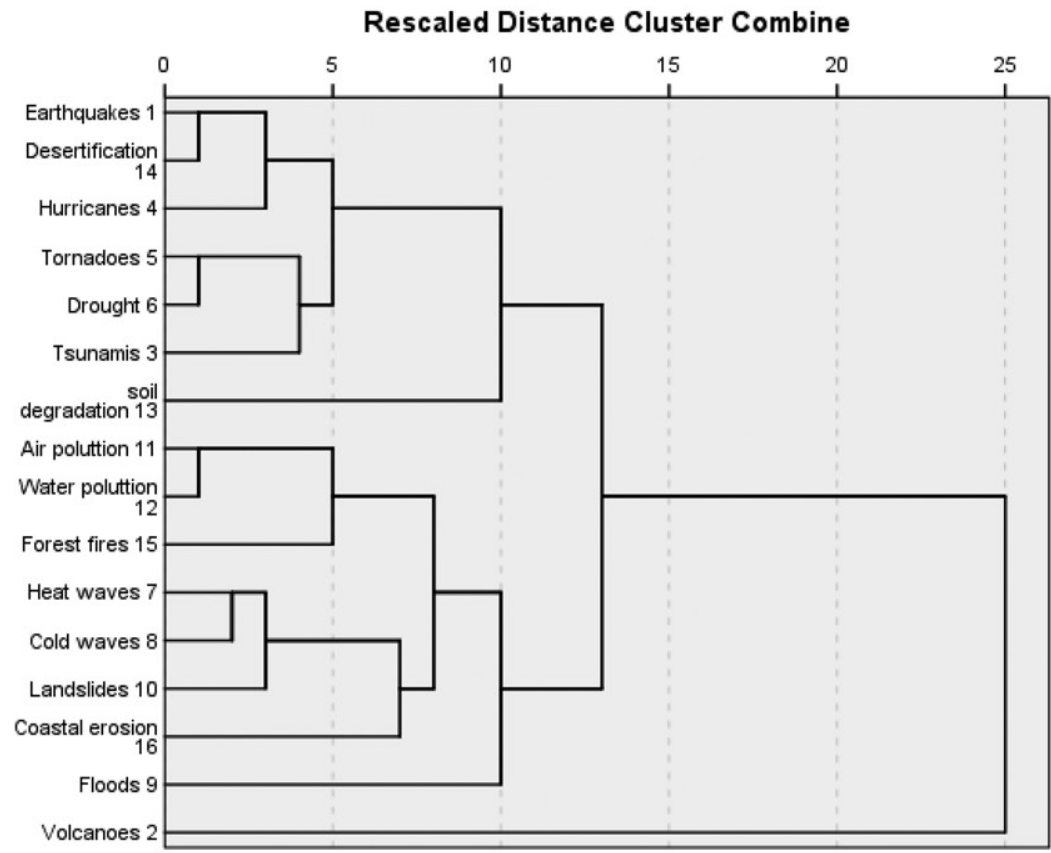

a) Porto

\section{Dendrogram using Average Linkage (Between Groups)}

\section{Rescaled Distance Cluster Combine}

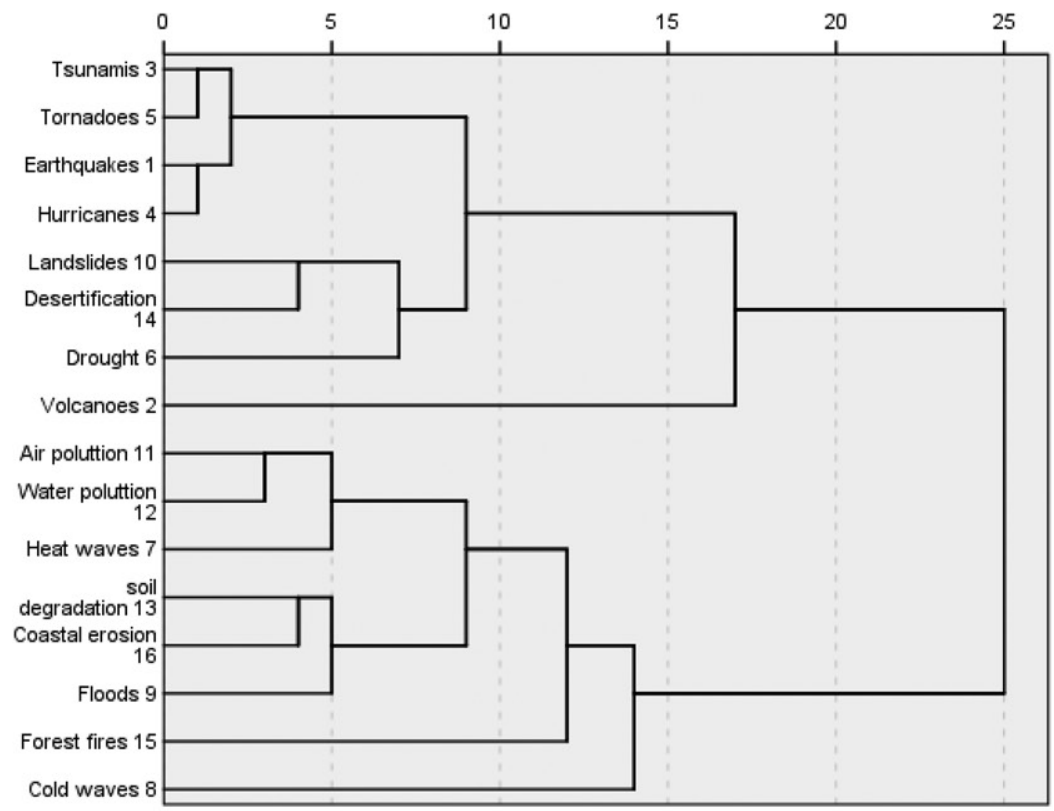

b) Gaia

Figure 5. Hierarchical cluster analysis regarding the occurrence of different risks, at municipal level. 
Dendrogram using Average Linkage (Between Groups)

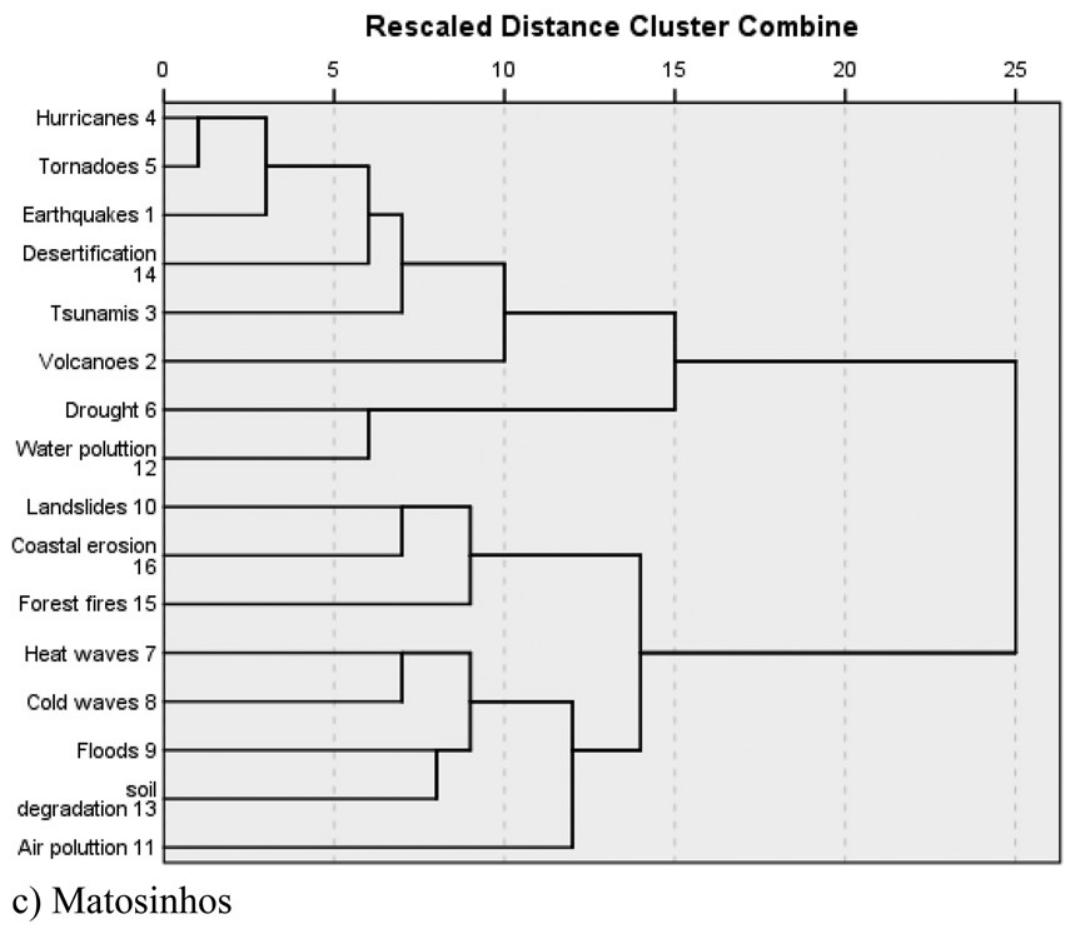

Dendrogram using Average Linkage (Between Groups)

Rescaled Distance Cluster Combine

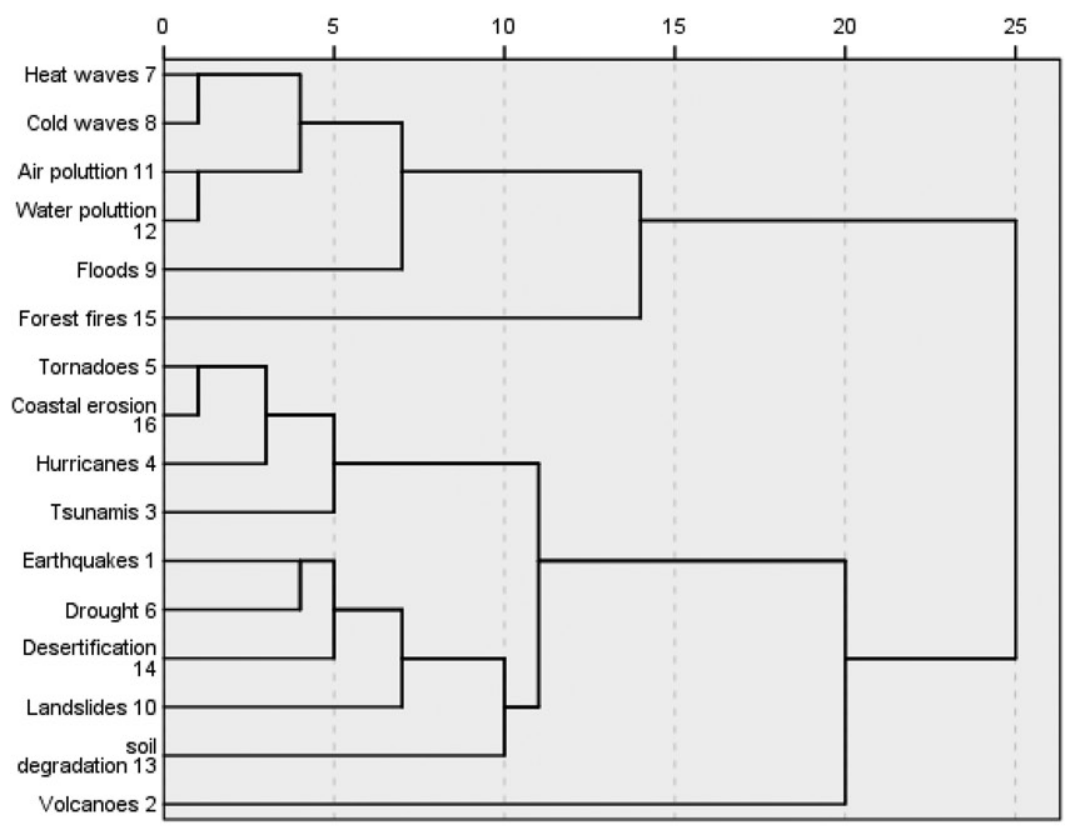

d) Gondomar

Figure 5. Continued 
Table 2. Pearson's correlation between risk ranking at national level and the municipalities in question.

\begin{tabular}{lccccc}
\hline & National & Porto & VNGaia & Matosinhos & Gondomar \\
\hline National & 1 & & & & \\
Porto & 0.517 & 1 & & & \\
VNG & 0.910 & 0.694 & 1 & 1 & 1 \\
Matosinhos & 0.881 & 0.829 & 0.824 & 0.746 & 1 \\
Gondomar & 0.895 & 0.580 & 0.929 & & \\
\hline
\end{tabular}

that are strongly linked to each other. Thus, the results for Matosinhos and Gondomar only differ in the ranking of landslides, soil degradation and water pollution, placed in the risk group with the high probability of occurring, for both (Figure $5 c, d$ ).

The Pearson coefficient was applied to measure the degree of students' association regarding the probability that a set of analysed risks will occur, both at national level and in the municipality where they live. The most significant finding was the correlation between the results obtained at national level and within the municipality of VNG $(r: 0.910)$. This shows a very similar perception of the probability of occurrence for the various types of risks addressed. Conversely, the lowest coefficient $(r: 0.517)$ is the one resulting from the correlation between the results obtained nationally and within the municipality of Porto.

In addition, considering the probability that natural and mixed risks will occur within the municipalities in question, the results are almost identical for the municipalities of VNG and Gondomar, given that correlation coefficient is 0.929 (Table 2).

\section{Causes, consequences and mitigation measures: what do the students know?}

Analysis of the results from the third section of the questionnaire, which relates to the students' knowledge of the causes, consequences and mitigation measures for the risk that they consider to be greatest, based on its number of occurrences, suggests that they have a number of difficulties regarding factors concerning the origin the risk as well as ways of mitigating it. Around $70 \%$ of the students did not respond correctly to the three questions asked. Of these, the Causes and Consequences have clearly received the highest number of incorrect answers, both with scores close to $75 \%$. With regard to mitigation measures, around $42 \%$ matched the correct measures to the identified risk (Table 3). Causes attributed to the risk of fires were "lack of clearing of forests" and "arson." The consequences cited were the "destruction of the forest" and "loss of housing and agricultural land." With regard to mitigation measures, the "existence of forest police," "less forest waste" and "clearing of forests", as well as "severe punishment for arsonists" stand out. With regard to the second most rated risk, water pollution, "not polluting" was the most popular mitigation measure, chosen by around $63 \%$, followed by "legislating and punishing those that pollute" (14\%), "construction of a waste water treatment centre" (11\%), and "inspecting pollutant emitters" (7\%). For the risk of air pollution, several mitigation measures were considered. "Using transport less and walking more" was the most popular measure, chosen by around half of the students, followed by "using public transport," "using renewable energy," "using electric cars," "reducing public sources of pollution," 
Table 3. Analysis of answers regarding knowledge of the causes, consequences and mitigation measures for the highest probability risk in the municipality where they live.

\begin{tabular}{|c|c|c|c|c|c|}
\hline \multicolumn{2}{|c|}{ Identifies causes } & \multicolumn{2}{|c|}{ Identifies consequences } & \multicolumn{2}{|c|}{$\begin{array}{c}\text { Identifies } \\
\text { mitigation measures }\end{array}$} \\
\hline Yes (\%) & No (\%) & Yes (\%) & No (\%) & Yes (\%) & No (\%) \\
\hline 25 & 75 & 22 & 78 & 42 & 58 \\
\hline
\end{tabular}

"reducing the number of factories," "relocating factories further away from people," "promoting recycling," "more green spaces" and "reducing greenhouse gases." With regard to the risk of flooding, the "construction of protective structures such as escarpments" was chosen by around $30 \%$ of the respondents, followed by "not building in high risk areas" (23\%), "improving the sewage system" (8\%), while "reducing pollution," "building dams," "increasing soil permeability," "recycling" and "educating the population and giving guidance for crises" all scored below $5 \%$.

Overall, we found a connection between the difficulty in responding to questions related to the origin, consequences and mitigation measures of natural risks and understanding the concepts of risk, disaster, susceptibility and vulnerability. In fact, the students failed to answer correctly in $\sim 70 \%$ of the questionnaires, which is confirmed by the fact that only $39 \%$ of them correctly answered the question on the concept of risk. This discrepancy is less marked with regard to the other concepts.

\section{Discussion}

Students' perception of risks, their intensity and their probability of occurrence is essential to risk reduction education and, therefore, to disaster risk reduction. Conceptually, some confusion about terminology was encountered, especially when concepts such as susceptibility, vulnerability and disaster were assessed. This difficulty was even more pronounced in a high number of students who could not identify the causes, consequences and mitigation measures associated with a risk, which, based on the probability of its occurrence, they considered to be the most important in the municipality where they live. Some authors (Gerstenmaier \& Mandl, 1995; Schubert, 2015) agree that all perceptions are interpreted in accordance with previous knowledge and ways of life, value systems and beliefs. Thus, poor knowledge or misunderstandings in students' perceptions about the concepts of risks, causes, consequences and mitigating measures of the most important local risk, shown by Portuguese students, can largely be put down to the facts that the content has not been taught and that these concepts are quite complex, involving interactions between natural (physical) and human (behavioural) factors (Eiser et al., 2012).

Conversely, the students have less difficulty in identifying the risks that had the greatest probability of occurrence, both at national level and in the area where they live. Moreover, the probability of occurrence that they attributed to their area of residence was, comparatively, always less than that stated on a national scale. These results agree with Mitchell (2009) who reports that when places or specific events are mentioned students are left with the impression that these are events that happen there, not here. These regional differences in risk perception may vary depending on 
the type of risk proximity, risk context, the personality of the individual and the social context, and the nature and type of information sources available (Dosman, Adamowicz, \& Hrudey, 2001; Wachinger et al., 2013). These factors are linked to indirect experience because an individual without direct experience of a hazard bases risk perception on external information such as mass media. In fact, the media proved to be an important and popular channel of information about the development and aftermath of local extreme phenomena. This source came well ahead of other formal sources of information, including schools and information campaigns (Biernacki, Działek, Janas, \& Padło, 2008). In Portugal, disasters (mainly forest fires and floods) are a significant source of news (television, newspapers, etc). The information provided by the mass media, the media coverage and the involvement of experts in risk analysis create indirect experience since individuals without direct knowlege need to base their risk understanding on external information (Siegrist \& Gutscher, 2006).

\section{Final considerations and further research}

This article has examined the perceptions of 9th year students about fundamental issues related to risks: the concepts, spatial incidence in mainland Portugal vs their place of residence, and the causes and consequences of, and mitigation measures for, the risk that they consider most likely to occur where they live. Altought the issue "risks and disasters" has been included in the formal curriculum since the beginning of the millennium we believe that the current geography teaching targets can play a key role in risk reduction education. This is not only an integrating subject, but also one that seeks to answer questions posed by humankind about the physical and human environment, which interact with one another and are constantly changing.

Because this study is largely exploratory, further empirical studies are needed to assess how to incorporate risk issues and content in formal education. This will contribute to the advancement of risk management and increase awareness of the causes and effects of, and mitigation measures for the type of disasters that currently affect Portugal. The application of the postponed questionnaire to allow the assessment of the impact on students' perceptions about risks as a result of the implementation of the new curriculum targets is the next challenge. The analysis of students' characteristics, parents' education, age, previous educational achievements, and extra-curricular activities are other variables that can interfere in perceptions of education quality. The qualifications of teaching staff and the quality of the content of didactic materials used in the teaching-learning process can be very important to the students' education and to their learning achievements.

\section{Funding}

This article was supported by NICIF (Centre for Scientific Research of Forest Fires) at the University of Coimbra and by the CEGOT (Centre for Studies in Geography and Spatial Planning), which is financed by national funds via the Foundation for Science and Technology (FCT) under the COMPETE project, reference POCI-01-0145-FEDER-006891 (FCT project: UID/GEO/04084/2013). 


\section{ORCID}

Bruno Martins (D) http://orcid.org/0000-0001-8681-2349

Adélia Nunes (D) http://orcid.org/0000-0001-8665-4459

Luciano Lourenço (D) https://orcid.org/0000-0002-2017-0854

\section{References}

Almeida, S. (2011). Reabilitação e segurançã do centro histórico de Vila Nova de Gaia um projecto de protecção civil, Tese de Doutoramento, Coimbra.

Ardaya, A., Evers, M., \& Ribbe, L. (2017). What influences disaster risk perception? Intervention measures, flood and landslide risk perception of the population living in flood risk areas in Rio de Janeiro state, Brazil. International Journal of Disaster Risk Reduction, 25, 227-237.

Bardsley, D. K. (2017). Too much, too young? Teachers' opinions of risk education in secondary school geography. International Research in Geographical and Environmental Education, 26(1), 36-53.

Battersby, S. E., Mitchell, J. T., \& Cutter, S. L. (2011). Development of an online hazards atlas to improve disaster awareness. International Research in Geographical and Environmental Education, 20(4), 297-308.

Becker, G., Aerts, J., \& Huitema, D. (2014). Influence of flood risk perception and other factor on risk reducing behaviour: A survey of municipalities along the Rhine. Journal of Flood Risk Management, 7 (1), 16-30.

Biernacki, W., Działek, J., Janas, K., \& Padło, T. (2008). Community attitudes towards extreme phenomena relative to place of residence and previous experience. In Liszewski S (ed). The influence of extreme phenomena on the natural environment and human living conditions (pp. 207-237). Łódz: Łódzkie Towarzystwo Naukowe.

Birkholz, S., Muro, M., Jeffrey, P., \& Smith, H. (2014). Rethinking the relationship between flood risk perception and flood management. Science of the Total Environment, 478, 12-20.

Bodoque, J. M., Amérigo, M., Díez-Herrero, A., García, J. A., Cortés, B., Ballesteros-Cánovas, J. A., \& Olcina, J. (2016). Improvement of resilience of

urban areas by integrating social perception in flash-flood risk management. Journal of Hydrology, 541, 665-676.

Cunha, L. E., \& Dimuccio, L. (2002). Considerações sobre riscos naturais num espaço de transição. Exercícios cartográficos numa área a Sul de Coimbra. Territorium, Coimbra, (9), 37-53.

Dixit, A. (2003). Floods and vulnerability: Need to rethink flood management. Natural Hazards, 28, 155-179.

Dosman, D. M., Adamowicz, W. L., \& Hrudey, S. E. (2001). Socioeconomic determinants of health- and food safety-related risk perceptions. Risk Analysis, 21(2), 307-318.

Eiser, J. R., Bostrom, A., Burton, I., Johnston, D., McClure, J., Paton, D., van der Pligt, J., White, M. P. (2012). Risk interpretation and action: A conceptual framework for research in the context of natural hazards. Journal of Disaster Risk Reduction, 1, 5-16.

EMAAC (2016). Estratégia de Municipal de Adaptação às Alterações Climáticas. Câmara Municipal Do Porto, Porto.

Gerstenmaier, J., \& Mandl, H. (1995). Wissenserwerb unter konstruktivistischer Perspektive. Zeitschrift Für Pädagogik, 41 (6), 867-888.

ISDR, International Strategy for Disaster Reduction. (2007). Towards a culture of prevention: Disaster risk reduction begins at school- good practices and lessons learned. United Nations: UNESCO, 153p.

Kaufman, L., \& Rousseeuw, P. J. (1990). Finding groups in data: An introduction to cluster analysis. Wiley series in probability and mathematical statistics. Applied probability and statistics, New York: Wiley.. 
Lebel, T. (2006). Invisible stripes? Formerly incarcerated persons' perceptions of and responses to stigma. Dissertation Abstracts International, 67 (2-A), 731A. UMI No. 0419-4209).

Leite, F., Gonçalves, A. B., \& Vieira, A. (2011). The recurrence interval of forest fires in Cabeço da Vaca (Cabreira Mountain-northwest of Portugal). Environmental Research, 111, 215-221.

Mitchell, J. T. (2009). Hazards education and academic standards in the Southeast United States. International Research in Geographical and Environmental Education, 18(2), 134-148.

Muttarak, R., \& Lutz, W. (2014). Is education a key to reducing vulnerability to natural disasters and hence unavoidable climate change? Ecology and Society, 19 (1), 42.

National Research Council. (2006). Learning to think spatially. Washington, DC: National Academies Press.

Nunes, A., Almeida, A. C. e., \& Nolasco, C. (2013). Educação para o Risco: contributo da Geografia no 3. ${ }^{\circ}$ ciclo do Ensino Básico. In L. Lourenço e M. Mateus (Coord. e Org.), Riscos naturais, antrópicos e mistos. Homenagem ao Professor Doutor Fernando Rebelo. Departamento de Geografia. Faculdade de Letras. Universidade de Coimbra, (Vol. 1, p. 123-132).

Nunes, A., Almeida, A. C., \& Nolasco, C. (2014). "Metas curriculares de geografia- $3^{\circ}$ ciclo do ensino básico". Ministério da Educação e Ciência.

Nunes, A., Lourenço, L., \& Meira, A. C. (2016). Exploring spatial patterns and drivers of forest fires in Portugal (1980-2014). The Science of the Total Environment, 573, 1190-1202.

Nunes, A. N. (2012). Regional variability and driving forces behind forest fires in Portugal, an overview of the last three decades (1980-2009). Applied Geography, 34, 576-586.

Oliveira, S., Laneve, G., Fusilli, L., Eftychidis, G., Nunes, A., Lourenço, L., \& Sebastián-Lopéz, A. (2017). A common approach to foster prevention and recovery of forest fires in mediterranean Europe. In Borna Fuerst-Bjeliš (Ed.), "Mediterranean Identities - Environment, Society, Culture". Chapter 14, InTech- Open Access Publisher, pp. 337-361.

Pestana, M. H. E., \& Gageiro, J. N. (1998). Análise de dados para Ciências Sociais-A complementaridade do SPSS. Lisboa: Edições Sílabo.

Portuguese National Statistics Institute. (2018). Census 2015. Lisboa: INE.

Ranger-Morgan. (1997). Public perception, understanding, and values In Richards, D. J., editor. The industrial green game: Implications for environmental design and management (pp. 200-211). Washington, DC: National Academy Press.

Rebelo, F. (2008). Um novo olhar sobre os riscos? OS exemplos das cheias rápidas (flash floods) em domínio mediterrâneo. Territorium, $\mathrm{n}^{\circ}(15)$ Coimbra, 7-14.

Schubert, J. C. (2015). Causes, processes and consequences of "desertification": Results of a qualitative study about the conceptions of 12- and 13-year-old students in Germany. International Research in Geographical and Environmental Education, 24(2), 148-166.

Siegrist, M., \& Gutscher, H. (2006). Flooding risks: A comparison of lay people's perceptions and expert's assessments in Switzerland. Risk Analysis, 26(4), 971-979.

Slovic, P. (1987). Perception of risk. Science (New York, N.Y.), 236(4799), 280-285.

Smith, K. (1996). Environmental hazards. Assessing risks and reducing disasters. London: Routledge.

Tedim, F., Ferreira, M., Cunha, M. A. E., \& Sousa, C. G. (2010). Risco de Incêndio Florestal no Ensino da Geografia no $3^{\circ}$ Ciclo do Ensino Básico. Ensino da Geografia e Processo de Bolonha. Actas do XII Colóquio Ibérico de Geografia, 6 a 9 de. Outubro Porto: Faculdade de Letras, Universidade do Porto.

UNISDR. (2009). Terminology on Disaster Risk Reduction, United Nations International Strategy for Disaster Reduction (UNISDR).

Wachinger, G., Renn, O., Begg, C., \& Kuhlicke, C. (2013). The Risk Perception paradoximplications for governance and communication of natural hazards. Risk Analysis, 33(6), 1049-1065. 